\title{
EL DIETARI DE PERE GIMFERRER. ESTRATĖGIES FICCIONALS EN L'ESCRIPTURA AUTOBIOGRÀFICA
}

\author{
ELOI GRASSET
}

\begin{abstract}
This article analyzes Pere Gimferrer's Dietari exploring the relation between fictional and autobiographical genres. It shows how the writer subverts generic stratification by defining the characteristics of autobiographical writing. Distinguishing two types of text in the Dietari, “associative", which corresponds to the expectations of the genre, and "dissociative", through which the author challenges established conventions, this analysis focuses on the latter and explains in detail the fictional changes that take place. Finally, this reading proposes Gimferrer's Dietari as a literary space that should be used to question the very notion of the genre of autobiography.
\end{abstract}

E aquest article, ens acostarem a les relacions que manté la ficció amb el gènere autobiogràfic. Són relacions inestables i complexes, sens dubte, com ho són totes les relacions de frontera. Un exemple d'aquesta dificultat que troba la crítica per determinar la relació que mantenen la ficció i la no-ficció és el fet que l'autobiografia ha estat presentada per alguns teòrics com un gènere oposat a la ficció (Lejeune I4), mentre que per alguns altres no és més que una altra possibilitat que troba l'escriptura ficcional per resoldre's (De Man 920).

Un dels escassos indicis que a priori ens haurien de servir per arribar a distingir el règim narratiu de la ficció del de l'escriptura autobiogràfica, dins de la qual podem incloure el Dietari de Pere Gimferrer, és la igualtat d'identitat que s'estableix entre l'autor, el narrador i el personatge. L'associació d'aquestes tres instàncies es troba a l'origen del "pacte autobiogràfic" tal i com l'ha definit Lejeune (I6), que és el pacte que s'estableix entre el l'escriptor i el lector sobre la veracitat dels esdeveniments que s'expliquen. En el Dietari de Gimferrer, hi trobem cert esperit transgressor davant del que suposa aquesta hipòtesi i això es manifesta a través de la posada en dubte d'aquest pacte, en el sentit que s'introdueixen en el text certes estratègies pròpies de la ficció.

En el Dietari de Gimferrer podem distingir dos grans models de textos. D'una banda, els textos que podem anomenar "associatius", que acompleixen la igualtat autor / narrador / personatge i que, una vegada admesa la "hipòtesi d'autenticitat" que reclama tot text autobiogràfic, no ens posen cap problema respecte a la seva factualitat. Parlarem de factualitat per referir-nos a la no-ficció seguint la terminologia de G. Genette (Fiction I 4I). Aquest model "associatiu" correspon perfectament a allò que esperaríem trobar en un Dietari, és a dir, Gimferrer existeix en una realitat $i$ al mateix temps assumeix la veracitat de certs esdeveniments explicats que hem d'entendre dins la xarxa de relacions que manté l'escriptor amb el seu temps. Aquests esdeveniments seran signes 
transformadors de la realitat de Gimferrer i, en conseqüència, hauran de ser entesos com un exercici d'interpretació de la pròpia circumstància. D'altra ban$\mathrm{da}$, tenim un model de textos que anomenarem "dissociatius" i que constitueixen el conjunt al qual ens agradaria parar atenció. El model "dissociatiu" ens indica un procediment invers respecte l'associativitat de la qual parlàvem abans: Gimferrer intentarà amagar-se darrera la seva escriptura. Encara que el paratext (Genette, Semils ıo) ens indiqui que estem llegint un dietari públic d'escriptor, és precisament aquesta allegació de factualitat la que sembla protegir l'autor per permetre-li produir un efecte ficcional. Gimferrer, en aquests textos, no es lliurarà pas a la retrospecció breu dels fets més recents que han esdevingut just abans de la datació de la seva escriptura, sinó que marcarà una distància temporal arbitrària, que no intervindrà en la selecció dels esdeveniments narrats, entre el temps de l'enunciació - és a dir, el moment imposat de facto per la datació en la qual s'acomoda l'escriptura- i el temps de l'enunciat. Totes aquestes precisions no impossibiliten, però, que la data que apareix en l'encapçalament de cada fragment del dietari no sigui decisiva en el procés d'escriptura, tot el contrari, ja que, tal i com va dir M. Blanchot (252), potser l'única característica del dietari és la submissió, de manera explícita, del text al calendari. Sota la protecció que ofereix la regularitat dels dies ordinaris, Gimferrer ens podrà explicar no només tota experiència viscuda simultàniament al temps de l'enunciació, sinó tota experiència que tingui una relació directa o indirecta amb la seva vida.

La datació es presenta com un element essencial de l'escriptura diarística i és aquest desenvolupament regular que la progressió temporal reclama, allò que defineix el vincle de Gimferrer amb el temps efectiu en el qual s'inscriu la seva escriptura. Com comenta Xavier Pla referint-se a les característiques formals dels dietaris:

L'única característica que unifica i singularitza, a primera vista, els diaris íntims és la presència d'una inscripció temporal que encapçala els fragments o alguns d'aquests fragments, encara que seria probablement una mica absurd intentar fixar la frequiència òptima, o mínima, d'aquesta pràctica. En tot cas, el que sembla inevitable és que hi aparegui una relació periòdica datada. Per aquesta raó, sembla indispensable citar el que el crític francès Jean Rousset, en una de les seves reflexions sobre els dietaris, va proposar anomenar la llei Blanchot, segons la qual la única regla del dietari seria la seva submissió explícita a un calendari regular. (396)

Una vegada analitzades les característiques particulars del gènere diarístic, cal que tornem a l'obra que ens ocupa. Els dos models de textos que acabem de definir ens permeten albirar ja la complexitat del moviment que es produeix en el text que tenim al davant, on es mostrarà la posada en dubte de tota possible definició estable de gènere que vingui definida per la instauració de certs esquemes convencionals. 


\section{TRANSVERSALITAT DE GÈNERES: DIETARI I FICCIÓ}

La inclusió d'estratègies pròpies de la ficció sembla incompatible amb la sinceritat esperada d'un enunciat com el que ofereix el dietari. Aquesta inadequació d'estratègies narratives a les expectatives que genera el text podria posar en dubte l'actitud de Gimferrer en relació amb el gènere. Aquesta vacillació, entre expectatives i estratègies, descobreix certa propensió convencional, importada directament de la poètica d'Aristòtil ( 145 I $b$ ), a convertir tota marca de literarietat en un signe revelador de ficcionalitat. Segons Aristòtil, si la literatura es diferencia de les altres arts és pel seu "medi d'imitació". Les obres literàries es diferencien entre si pel seu registre - els "objectes a imitar", segons Aristòtil. Aquestes imitacions poden ser realitzades en diferents tons —alt, mitjà o baixi això és el que constitueix els diferents modes d'imitació que corresponen als diferents gèneres. Més que no pas organitzar les possibilitats creatives, el que pretén Aristòtil amb aquestes classificacions és donar un seguit d'eines per poder exercir la crítica literària (Garrido Gallardo io). De tota manera, a partir d'aquest moment, la literatura queda enllaçada a la ficció i per aquesta raó l'escriptura diarística planteja problemes teòrics importants vinculats a la ficcionalitat. Com explica Genette:

La réponse d'Aristote est claire: il ne peut y avoir de création par le langage que si celuici se fait véhicule de mimèsis, c'est-à-dire de représentation, ou plutôt de simulation d'actions et d'événements imaginaires... Pour Aristote, la créativité du poète ne se manifeste pas au niveau de la forme verbale, mais au niveau de la fiction, c'est-à-dire de l'invention et de l'agencement d'une histoire. (Fiction 96)

Si tenim això en consideració i tornem al Dietari de Gimferrer, hem de reconèixer l'absència de tot pacte referencial en els textos que hem definit com a "dissociatius". D'aquesta manera, el lector atribuirà sense cap problema una existència ficcional als diferents personatges que van apareixent en els textos. Recordem a propòsit d'això que l'autor escriu sobre petits instants de la vida d'escriptors, músics, actors o personatges ficcionals, tot construint l'espai de l'escriptura allunyat de la contingència del temps present. Certament, la presència d'un narrador extern als esdeveniments no constitueix un criteri suficient de la ficció. El que és innegable, però, és que si trobem un narrador extern que no participa de l'acció, en un gènere tan codificat com és el dietari, estarem casi obligats a creure en la tendència volgudament ficcional que amaga el discurs.

Les estratègies enunciatives utilitzades pel narrador, $i \mathrm{amb}$ les quals intentarà introduir elements ficcionals en les seves entrades diàries, tenen a veure amb el decalatge existent entre el temps de l'enunciat i el temps de l'enunciació. Utilitzat de forma totalment deliberada pel narrador, es produeix en el text tan aviat un efecte de proximitat com d'allunyament, establint-se, de manera contínua, una ambivalència entre els diferents temps emprats. Això és el que portarà, per exemple, Josep M. Castellet a parlar de la "simultaneïtat històrica" del 
Dietari (13). D’aquestes estratègies cal destacar l'ús de l'“anticipació”, que fa que el narrador avanci esdeveniments posteriors a la situació narrada:

Encara faltaven dos dies per a l'equinocci de tardor —és a dir, encara no havia començat verament la tardor-quan aquell noi va escriure el seu poema. Era el ig de setembre de I 8 I9, i ell tenia vint-i-tres anys; només viuria fins als vint-i-cinc, i la mort d'aquell noi - que es deia John Keats i era un gran poeta- és un d'aquests fets però alhora dolorosament closos en una mena de lògica interna, de necessitat, fèrria i profunda... En aquell setembre remot i suau, John Keats era a Winchester. Havia deixat momentàniament d'escriure's amb la seva estimada (Gimferrer, Dietari I 54)

El narrador anticipa els fets que tindran lloc en el text i, al mateix temps, atesta que la vida del protagonista del fragment continua més enllà dels límits de la narració. Utilitza, doncs, el que Genette anomena "prolepsis externes” (Figures I06), que tenen per funció fer d'epíleg del text i serveixen per conduir fins al seu terme lògic la línia d'acció explicada, tot i que sigui posterior a la narració.

Crida també l'atenció l'alteració constant del codi focalitzador dominant a través de la qual el narrador omet els noms dels personatges protagonistes fins a la fi dels textos, per crear una certa suspensió de la "intriga". Aquesta estratègia, emprada normalment en textos de ficció, pot semblar massa complexa per un dietari, però Gimferrer se'n serveix per mantenir fins al final l'ambigüitat referencial del fragment. Aquest ús està fortament lligat a la utilització d'anafòrics sense antecedent. Gimferrer introdueix sovint els personatges que apareixen en les seves anotacions del dietari amb un pronom personal que no reenvia a cap segment anterior del discurs, produint així un efecte d'estranyesa en el lector:

Corpulent, el patriarca arribava aquí. Algú força més jove ens ho ha explicat. La gent pel carrer el coneixia, potser l'aturava i tot: d'altres de lluny o de prop, el miraven passar. Ell era a tot arreu: enmig de la gernació, [...] o bé covant somnis dins la solemnitat polsosa dels prestatges antics de les grans biblioteques ventejades. (Dietari I I 2$)^{\mathrm{I}}$

Amb l'abús d'aquest procediment, típicament ficcional, es mira de mantenir una certa dialèctica mistificadora de la informació que el text transmet. L'absència de noms provoca en el lector una deflació de la illusió referencial basada, precisament, en la imposició de noms. Un text factual, com podria ser el cas d'un dietari canònic, ${ }^{2}$ es caracteritza en canvi per ser un text "saturat" d'anafòrics amb antecedent a través dels quals el narrador intenta assegurar la cohesió i, al mateix temps, fer desaparèixer l'ambigüitat de la informació.

Una altra estratègia específicament ficcional que cal destacar és l'ús enganyós dels díctics temporals que, després que s’hagi produït una alteració de la situació enunciativa a partir d'una ruptura del discurs, ja no ens remeten al moment de l'enunciació sinó al temps de l'enunciat. Això es produeix quan l'autor utilitza una localització temporal absoluta que ens permet situar l'esde- 
veniment i, posteriorment, fa servir díctics temporals que ens envien a la nova situació d'enunciació ficcionalitzada:

Som a Dublín el 4 de juny de i904. El cuiro dels seients fa un carrisqueig. En la calma de cella, sota la volta solemne del sostram, un llum amb casqueta verda. I ara Stephen Dedalus - que no ha pas dinat, tot i que són més de les dues del migdia, però té uns quants gots de vi al cos - ho comenta inconnex i vehement, a l'auditori desballestat — un poeta local, un bibliotecari quàquer-que l'escolta. (Gimferrer, Dietari I I9I) ${ }^{3}$

El narrador ens transporta aquí al novè capítol de l'Ulysses de James Joyce, i diem que ens hi situa perquè evidentment hi ha una alteració del temps de l'enunciació que deixa de ser el divendres i9 de setembre de i980, tal i com indica la datació del fragment del Dietari, i passa a ser el 4 de juny de i 904, data en la qual es situa la primera frase del text i que serveix de localització temporal absoluta. L'ús del díctic temporal ara, relatiu doncs a partir d'ara al temps de l'enunciació — - i fem al:lusió aquí al moment precís de la recepció del text- fa referència al temps de la ficció de la novellla. En el tipus de discurs factual, normalment els díctics temporals fan referència al temps d'aquell qui enuncia, mentre que en el discurs ficcional són sovint referits a la tercera persona, com en aquest cas. En una altra variant d'aquest procediment, el narrador no utilitza la localització temporal absoluta, sinó una localització relativa al temps de l'enunciat que roman elidit. Només havent llegit tot el text, podrem emplaçar la situació enunciativa. Un exemple pot ser aquest text en el qual se'ns parla del poeta rus Alexandr Puixkin:

No: aquest poeta ara, no el trobareu pas al camp. De més jove, hi havia viscut, i en una carta parlava dels fondos abismes i del vol alt, noble i solitari de les àguiles, i de la verdor estesa i onejadora de les estepes... Ara, però, el trobareu als salons. (Gimferrer, Dietari I 283)

Amb aquest procediment, podem detectar la pretensió del narrador de relacionar el passat i el present a través de la ficcionalització de certs esdeveniments. El temps de la narració és el present contemporani de l'acció i el narrador, seguint un clàssic procediment d'escriptura diarística, fa coincidir el temps - d'altra banda fictici- de l'escriptura amb la cronologia dels fets narrats $i$ amb el temps del treball real de l'autor. La confusió de presents que es produeix mostra la subordinació de la narració a una subjectivitat modalitzant. Al mateix temps, ens assenyala certa inestabilitat que s'instaura entre el discurs factual garantit tan sols pel paratext i la desviació ficcional del text. Hi ha, doncs, una clara voluntat d'instaurar una narració simultània entre la cronologia de la narració i la del narrador, tot i que les indicacions de data del Dietari ens permetin distingir la separació entre el temps narrat i el temps efectiu d'escriptura -és a dir, el nivell “extratextual” “extradiegètic”.' L'esdeveniment és entès com a contemporani de l'acte de lectura, i aquesta és, precisament, una de les propietats del temps de la narració ficcional: poder posar-se com a contemporània del temps de l'esdeveniment que s'explica. 
Aquestes particularitats dels textos que hem definit com a "dissociatius" ens indiquen una sèrie de trets definitoris que semblen aproximar l'escriptura de Gimferrer als procediments utilitzats en la ficció. Tot i que no siguin característiques definitives per poder parlar d'una narració ficcional - ja que tal i com hem indicat més amunt, només hi ha indicacions paratextuals i condicions extralingüístiques no semàntiques que puguin decidir sobre la ficcionalitat de l'escriptura (Searle 62) - ens sembla important observar com aquest seguit de propietats constitueixen indicis que ens han de permetre entendre la voluntat d'integrar la ficció en l'espai factual de l'escriptura gimferreriana.

Les característiques que acabem de descriure, vinculades a la ficcionalització dels textos "dissociatius" del Dietari, són sintagmàtiques. Amb això volem dir que aquest seguit d'estratègies no afecten el sentit $i$, per tant, no estan vinculades a la competència semàntica del locutor. En conseqüència, no canvien el sentit de cap mot ni de cap altre element de la llengua, sinó que vénen a constituir el que nosaltres hem anomenat un moviment horitzontal - ja que es produeixen a nivell sintagmàtic - que està desvinculat de les estratègies lligades a la dinàmica referencial del text a les quals ara pararem esment.

\section{Problema Referencial dels textos “Dissociatius”}

El fet que els textos dels quals parlem estiguin integrats en una obra com el Dietari implica, inevitablement, una sèrie de convencions que hauran de permetre mantenir certa hipòtesi d'autenticitat (Lejeune 30). La integració d'aquestes convencions sembla necessària per posar en relació la xarxa de significacions que s'estableixen entre el text i el món. Hem de concebre-les, doncs, com unes regles que estableixen connexions verticals, necessàries entre llenguatge i realitat, i que estan destinades a assegurar la relació entre el significat i el referent. El fet que en els textos "dissociatius" es produeixi el "moviment horitzontal" que hem descrit podria justificar que no es faci cap referència directa a la realitat contingent que correspondria a la datació del fragment.

En els textos de ficció es produeix un distanciament del referent perquè el discurs no envia a referents reals sinó essencialment ficcionals. Així, des del punt de vista estrictament lingüístic, el discurs ficcional es defineix per la denotació nulla de les descripcions definides, els noms propis o els díctics, que encara que tinguin un sentit són denotativament buits perquè no ens remeten a cap element referencial. Amb la presència d'aquest seguit de denotacions nulles, integrades en l'espai del Dietari, Gimferrer insisteix en la necessitat d'entendre, dins l'espai literari, que tot discurs - ficcional o factual — obeeix a un seguit de convencions igualment arbitràries. Al mateix temps, l'autor manté el dubte davant del lector, que tot i admetre, de iure, la distinció factual / ficcional es veu impellit a abolir les fronteres entre ficció i qualsevol altre tipus de discurs.

Els vincles del text amb el món vénen representats per diferents estratègies. En primer lloc, tenim les "referències històriques" amb les quals Gimferrer fa 
allusió al context històric en el qual es desenvolupa l'esdeveniment explicat. L'autor inclou en els seus textos referències històriques exteriors al discurs en les quals quedarà confós el significat del text. Aquest fet pot ser entès, en la manera en què el referent històric confronta el lector no al llenguatge sinó a la realitat mateixa, com un exemple del que Roland Barthes en deia "efecte de realitat” (I79). Com llegim a Gimferrer:

El 3 de juliol, ja en la sequedat de tralla de l'estiu a l'altiplà. Velázquez arriba baldat a Madrid, perquè durant tot el viatge no ha fet més que caminar de nit - no es podia viatjar sota l'assolellada - i treballar de dia. Morirà el 6 d'agost, i el i 2 la muller, ombra esborradissa i muda. Un gran silenci, com un espai en blanc al fons d'una tela, o com aquelles figures vites tènuement en un mirall a "Las Meninas". (Dietari I I 54$)^{6}$

La introducció de les dates precises del esdeveniments contrasten amb la presència d'elements que ens parlen d'unes condicions ficcionalitzades del viatge que es relata. La funció d'aquests elements "històrics" - les dates precises-, com ho era per Barthes el baròmetre que apareixia en el conte Un coeur simple de Flaubert, no és altra que poder atestar la veracitat dels esdeveniments que s'expliquen.

Un altre vincle utilitzat és la "referència nominal": Gimferrer no crea cap personatge en el seu Dietari. Podem trobar, en els seus textos, "personatges històrics" i "personatges ficcionals" i, en ambdós casos, la seva presència indica una adhesió a l'obra d'elements referencials que pertanyen a diferents àmbits: el referent històric en el cas dels personatges històrics i el referent ficcional en el cas dels personatges ficcionals. Gimferrer no fa cap tipus de diferència ontològica entre els dos tipus de personatges tot i que els personatges ficcionals denotin la seva absència palpable del món. La manera de què parla dels personatges ficcionals indica que aquests són emprats com qualsevol altre nom propi, com a designadors rígids units a certs individus particulars que continuen referint-hi malgrat els possibles canvis de les seves propietats $\mathrm{i}$ les variacions que puguin modificar la nostra coneixença del personatge en qüestió. Així, doncs, estructuralment parlant, no podem considerar cap diferència d'ús entre noms propis ficcionals i històrics. Aquest ús indistint fa explícita la intenció de l'autor de convertir l'espai del Dietari en un espai que vivifiqui els éssers ficcionals. Funciona, d'aquesta manera, una certa transitivitat entre el món i la factualitat de la qual participa el Dietari. Aquest fet no té lloc en els textos ficcionals perquè són intransitius, no pas perquè els seus enunciats no tinguin l'estatut ontològic, sinó perquè els personatges al quals s'adhereixen no tenen existència fora d'ells $i$ ens hi reenvien. La transitivitat que anunciàvem ens explica el fet que els textos de Gimferrer incloguin tan sols personatges que existeixen fora dels propis textos i n'assegurin la referencialitat reclamada pel "pacte d'autenticitat" del qual ens parla Lejeune.

La darrera estratègia que utilitza Gimferrer per posar en relació els textos “dissociatius" i el món és la cita. L'autor introdueix fragments de textos de dife- 
rents autors per unificar el referent i l'esdeveniment contat. L'ús del discurs directe serveix a l'autor per delegar la responsabilitat de veritat del discurs. No ho haurem de llegir com una simulació, ja que fa allusió a certs textos existents, sinó com un discurs que intenta insistir en la garantia de factualitat del text presentat:

Aquell que jo vaig ser, el poeta lleuger del amors tendres, aquell que tu llegeixes, aprèn a conèixer-lo, posteritat!" Qui parla és Ovidi, exiliat al pont Euxí, en un clima aspriu i inhòspit, entre gent que sovint ni tan sols parlaven llatí, per uns motius que encara no sabem, ni possiblement no sabrem mai de manera certa.(Gimferrer, Dietari I 27) ${ }^{7}$

Tot i així, no s'haurà d'entendre la citació com una simple repetició d'un enunciat. L'acte de citar habilita també la singularitat de l'enunciat i en tant que enunciat té un sentit vinculat a aquesta "segona" ocurrència. Ara bé, el sentit de l'enunciat original no és radicalment eliminat i aquí és on es fonamenta l'interès factual de l'aparició d'aquestes frases en el Dietari. Com comenta Antoine Compagnon:

Le sens survit à la citation: il est là, en sommeil ou en réserve, évoqué de manière indirecte, par l'intermédiaire de la dénotation de la citation. Le sens du mot cité est éloigné de deux degrés de la citation mais la chaîne qui les relie l'un à l'autre n'est pas tranchée, elle peut être parcourue afin que la réception de la citation réalise simultanément le sens de $« t »$ et le sens de $t .(87)$

Amb la introducció d'aquest seguit d'estratègies ficcionals l'autor ens mostra com la literatura pot convertir-se en un multiplicador del món i que escriure només podrà ser-ho en un sentit absolut. Com deia Barthes, aconseguir fer coincidir l'acció i l'afecció (29). La imaginació ficcionalitzant de Gimferrer acompleix, doncs, no tan sols una funció mimètica i descriptiva sinó una funció projectiva que li haurà de permetre crear un "nou efecte de referència" que ajudi a desestabilitzar els esquemes definidors del gènere establerts a mode de calcificació normativa esdevinguda convenció:

Écrire moderne: écrire, c'est aujourd'hui se faire centre du procès de parole, c'est effectuer l'écriture en s'affectant soi-même, c'est faire coïncider l'action et l'affection, c'est laisser le scripteur à l'intérieur de l'écriture, non a titre de sujet psychologique [...], mais a titre du verbe de l'action. (Barthes 29)

En aquest sentit, podríem considerar que el Dietari de Pere Gimferrer pot ser un exemple del que s'ha definit com la teoria integracionista de la ficció ( $\mathrm{Pa}$ vel I9), al no considerar cap diferència ontològica entre la ficció i les descripcions no fictícies de l'univers. Gimferrer, de la mateixa manera que els defensors de les teories integracionistes, retira tota especial consideració de veritat davant dels textos factuals - en el sentit que siguin confrontables a la realitat referencial- $\mathrm{i}$ a la vegada manté l'escepticisme davant la possible factualitat de qualsevol text, fet que l'obliga a abolir les fronteres entre ficció i no ficció per la simple raó que 
tot discurs obeeix a convencions igualment arbitràries i sense cap junció amb la veritat. Poder desfer-se del que $\mathrm{R}$. Barthes en deia la ideologia totalitària del referent (Barthes I79) permet incorporar a l'escriptura una dimensió creativa que implica la presa de riscos, la recerca dels límits i pot conduir, amb el temps, a l'establiment de nous esquemes convencionals que reorganitzin el pacte entre l'autor i el lector. Aquesta incorporació de nous models textuals es percep ara com a marginal només per oposició a la fixació cultural temporalment elevada a rang de norma que representen els gèneres literaris. Aquí es fonamenta la crítica del Dietari de Gimferrer que es pot llegir com una posada en dubte de tota possible institucionalització o formalització del gènere que intenti convertir la forma literària en una manera de detectar una intimitat constituïda fora del llenguatge. El Dietari no serà doncs considerat per Gimferrer un gènere, sinó un espai per qüestionar la noció mateixa de gènere. El Dietari és una figura de lectura i de coneixement indecidible que s'esdevé en tot text.

ELOI GRASSET

UNIVERSITAT DE BARCELONA

\section{REFERÈNCIES}

Aristòtil. Poètica. Barcelona: Edicions 62, I998.

BARTHEs, Roland. Le bruissement de la langue. Essais critiques IV. París: Seuil, I 984 .

Blanchot, Maurice. "Le journal intime et le récit”. Le livre à venir. París: Gallimard, I955. $252-260$.

Castellet, Josep M. "Introducció" in Gimferrer, Pere. Obra Catalana Completa 2. Dietari Complet, I (I979-1980). Barcelona: Edicions 62, I995. 5-I6.

Compagnon, Antoine. La seconde main. París: Éditions du Seuil, I979.

Lejeune, Philippe. Le pacte autobiographique. París: Éditions du Seuil, 1975.

De Man, Paul, “Autobiography as a De-Facement”. Modern Languages Notes 94 (I 979): 919-930.

Garrido Gallardo, Miguel Ángel. "Una vasta paràfrasis de Aristóteles”. Teoría de los géneros literarios. Ed. Miguel Ángel Garrido Gallardo. Madrid: Arco Libros, I998. 7-I4.

Genette, Gérard. Figures III. París: Éditions du Seuil, 1972.

-. Senils. París: Éditions du Seuil, 1987.

- Fiction et diction. París: Éditions du Seuil, r 99 I.

Gimferrer, Pere. Dietari Complet, I (1979-1980). Obra Catalana Completa 2. Barcelona: Edicions 62, I995.

-. Dietari Complet, 2 (1980-1982). Obra Catalana Completa 3. Barcelona: Edicions 62, 1996.

Pavel, Thomas. Univers de la fiction. París: Éditions du Seuil, I986. 
PLA, Xavier. Josep Pla: ficció autobiogràfica i veritat literària. Barcelona: Quaderns Crema, I 997.

SEARLE, John. "The logical status of fictional discourse". Expression and Meaning: Studies in the Theory of Speech Acts. Cambridge: Cambridge UP, 1979. $58-75$.

\section{Notes}

I Altres exemples significatius: Gimferrer, Dietari II I 2, 224, 232, 24I, 259.

2 Poden servir com a exemple de dietari canònic els textos "associatius" del mateix Dietari de Gimferrer.

3 Altres exemples: Gimferrer, Dietari I I 34, I 53; Gimferrer, Dietari II 34, I06, I43, I49.

4 Altres exemples: Gimferrer, Dietari I 33, 74, 2 I 8, 236.

5 El nivell extradiegètic del relat és aquell en què la veu narrativa no participa en la història (vegeu Genette, Figures 48).

6 Altres exemples: Gimferrer, Dietari I I 27, I38, I 53, 226, 236; Gimferrer, Dietari $I I 73,75$, I 84 .

7 Altres exemples : Gimferrer, Dietari I 3 I, 4 I, 54, 85, I 53, 348; Gimferrer, Dietari II I 29, I7I. 